\title{
Investments in Times of Pandemics: An Approach by the SAPEVO-M-NC Method
}

\author{
Sérgio Mitihiro do Nascimento MAÊDA ${ }^{\mathrm{a}, \mathrm{d}, 1}$, Marcio Pereira BASÍLIO ${ }^{\mathrm{b}}$, Igor Pinheiro \\ de Araújo COSTA ${ }^{\mathrm{a}, \mathrm{d}}$, Miguel Ângelo Lellis MOREIRA ${ }^{\mathrm{a}, \mathrm{d}}$, Marcos dos SANTOS ${ }^{\mathrm{c}, \mathrm{d}}$, \\ Carlos Francisco Simões GOMES ${ }^{\mathrm{d}}$, Isaque David Pereira de Almeida ${ }^{\mathrm{a}}$ and Arthur \\ Pinheiro de Araújo Costa ${ }^{\mathrm{d}}$ \\ ${ }^{a}$ Federal Fluminense University, Brazil \\ ${ }^{b}$ Military Police of the State of Rio de Janeiro, Brazil \\ ${ }^{c}$ Military Institute of Engineering, Brazil \\ ${ }^{d}$ Naval Systems Analysis Center, Brazil
}

\begin{abstract}
The consequences of the pandemic caused by the new coronavirus in the most diverse sectors of the Brazilian economy, are overwhelming, and its effects are still difficult to measure completely. There are several possible scenarios being considered, such as prolonged depression, "U" or "V" recovery. Due to such volatility, risks and uncertainties, the investor, before investing, must carefully analyze the alternatives available in the market. Given the above, this article aims to propose different ways of distributing a financial portfolio, considering five investment funds, which were evaluated in the light of five criteria, by two investors who work in the financial market. Therefore, the SAPEVO-M-NC multicriteria decision aid method was used to evaluate the alternatives, as well as their composition in the investment portfolios. The adoption of the methodology made it possible to carry out the distribution of the portfolio in a clear and consistent way, showing itself as an efficient practical tool for the proposed approach.
\end{abstract}

Keywords. Pandemic, COVID-19, Investments, Multicriteria decision aid

\section{Introduction}

The consequences of the new coronavirus pandemic, caused by the new coronavirus in the most diverse sectors of the Brazilian economy, are overwhelming and its effects in the medium and long term are still difficult to measure [1][2]. Uncertainties result in the flight of foreign capital and influence investments by national organizations in companies in more developed countries and with varied and consolidated corporate governance structures, thus seeking to mitigate investment risks [3]. During the decisionmaking process, the evaluator will come across different information, often conflicting with each other[4][5][6]. To provide greater transparency to the process, as well as to mitigate possible errors involved, the research sources must be exhaustively consulted,

${ }^{1}$ Corresponding Author, Sérgio Mitihiro do Nascimento Maêda, Federal Fluminense University - UFF, 24210-240, Niterói, Brazil; E-mail: sergiomnmaeda@gmail.com.

This research was financially supported by Military Police of the State of Rio de Janeiro. 
using reliable publications, which must be refined according to the research objective, providing the evaluator with the tools needed for a more accurate decision-making [7][8][9].

This article aims to propose the distribution of a financial portfolio, considering five investment funds, which were evaluated considering five criteria, by two investors who operate in the Brazilian financial market. Therefore, the SAPEVO-M-NC (Simple Aggregation of Preferences Expressed by Ordinal Vectors -Multi Decision Makers NonCompensatory) multicriteria decision aid (MCDA) method was used to evaluate the alternatives, as well as their distribution in the investment portfolios. The adoption of the methodology made it possible to carry out the distribution of portfolios in a clear, robust way and with relatively low cognitive effort on the part of decision makers (DM).

\section{Materials and methods}

In this section, the alternatives, criteria, and the SAPEVO-M-NC method will be presented. To assess the importance of the criteria and the performance of the alternatives, interviews were conducted with two professionals $\left(\mathrm{DM}_{1}\right.$ and $\left.\mathrm{DM}_{2}\right)$ who work in the financial market. It is noteworthy that these are not specialists in investments, having in this activity a means of increasing their earnings in the medium and long term. Asked about their investment profiles, $\mathrm{DM}_{1}$ declared itself as a "moderate" profile investor, while $\mathrm{DM}_{2}$ declared itself as an investor between "moderate and bold" profiles.

\subsection{Alternatives}

The alternatives indicated to compose the investment options in this article were selected from a Brazilian investment broker with great influence on the financial market.

Investment $A_{1}$ (FJPF): Post-fixed fixed income investment fund that invests at least $80 \%$ of the portfolio in federal government bonds and/or assets with low market credit risk. In this fund, when interest rates are high, yields tend to rise and when interest rates fall, profitability tends to show the same direction.

Investment $A_{2}$ (FJPR): Fixed-income investment fund, with exposure to real and nominal interest in Brazil and the possibility of operating in the international market, seeking medium and long-term yields above the CDI in different scenarios.

Investment $\mathrm{A}_{3}$ (FM): Multimarket investment fund exposed to various types of assets, such as interest, government bonds, foreign exchange, domestic and foreign shares, and variable income, offering more freedom for the manager to assemble the investment strategy, exploring opportunities in different scenarios.

Investment $\mathrm{A}_{4}(\mathrm{FA})$ : Stock fund that has exposure to a portfolio composed of stocks that seek to monitor the performance of the Ibovespa (Brazil stock exchange), being diversified and representing the behavior of the stock market.

Investment $\mathrm{A}_{5}(\mathrm{FC})$ : Fund with exposure to financial assets related to the US dollar, which aims to reduce the risks of exchange variation, or for investors seeking an investment linked to the variation of the US dollar.

\subsection{Criteria}

Criterion $\mathrm{C}_{1}$ - Profitability: indicates the percentage of return on invested capital, being a monotonic profit criterion, that is, the higher the better. 
Criterion $\mathrm{C}_{2}$ - Risk: represents the investment security levels, which will be considered market and credit. In this article, this criterion was classified using a 4-point scale, ranging from grade 0 , which represents zero risk, to grade 5, high risk.

Criterion $\mathrm{C}_{3}$ - Liquidity: ease of investment being "transformed into cash" without significant losses in its value. It should be noted that some of the investments have a previously established withdrawal date.

Criterion $\mathrm{C}_{4}$ - Volatility: Defined as the variation, over time, of the conditional variance of a time series. The perception of damage generated by the loss is 2.25 times greater than the sense of benefit produced by the gain, thus, this criterion will be considered of a monotonic cost nature, being the worse, the more expressive.

Criterion $\mathrm{C}_{5}$ - Initial application: Minimum amount required by the financial institution so that the investor can join the investment alternative. A high initial contribution acts preventing the access of less capitalized investors to the considered asset; thus, this criterion will also be considered of a monotonic cost nature.

The table 1 presents the data for the selected investments.

Table 1. Data on evaluated investments

\begin{tabular}{lccccccc}
\hline Investment & $\begin{array}{c}\text { Profitability in } \\
\text { the last 12 } \\
\text { months }\end{array}$ & $\begin{array}{c}\text { Average } \\
\text { profitability }\end{array}$ & Risk Liquidity & $\begin{array}{c}\text { Volatility in } \\
\text { the last 12 } \\
\text { months }\end{array}$ & $\begin{array}{c}\text { Annualized } \\
\text { volatility }\end{array}$ & $\begin{array}{c}\text { initial } \\
\text { application }\end{array}$ \\
\hline $\mathrm{A}_{1}$ (FJPF) & $2,40 \%$ & $5,45 \%$ & 1 & $\mathrm{D}$ & $0,31 \%$ & $0,24 \%$ & $\mathrm{R} \$ 1,00$ \\
$\mathrm{~A}_{2}$ (FJPR) & $4,35 \%$ & $3,53 \%$ & 2 & $1+\mathrm{D}$ & $0,93 \%$ & $0,97 \%$ & $\mathrm{R} \$ 500,00$ \\
$\mathrm{~A}_{3}$ (FM) & $7,39 \%$ & $21,11 \%$ & 3 & $17+\mathrm{D}$ & $1,21 \%$ & $1,45 \%$ & $\mathrm{R} \$ 50.000,00$ \\
$\mathrm{~A}_{4}$ (FA) & $18,38 \%$ & $18,93 \%$ & 4 & $30+\mathrm{D}$ & $40,40 \%$ & $25,2 \%$ & $\mathrm{R} \$ 15.000,00$ \\
$\mathrm{~A}_{5}$ (FC) & $25,30 \%$ & $12,03 \%$ & 4 & $1+\mathrm{D}$ & $19,7 \%$ & $15,9 \%$ & $\mathrm{R} \$ 1,00$ \\
\hline
\end{tabular}

\subsection{The SAPEVO-M-NC Method}

Derived from the SAPEVO-M ordinal method [10], the SAPEVO-M-NC method [11], consists of an ordinal method, non-compensatory nature, which aims at the problem of ordering ( $\mathrm{P} \gamma)$, and with the possibility of acting by multiple decision makers. In the method, the evaluation of the performance of the alternatives is carried out directly, with no need to carry out parity comparisons between the alternatives to obtain the modeling of preferences between them, resulting in a substantial reduction in the cognitive effort on the part of the DMs. The method also allows evaluating the rate of over classification between the alternatives. This information enables not only the DM to verify the dominance relationship, but also to identify, in percentage terms, how much one alternative outperforms the other [11].

Unlike Classic Decision Theory, which basically considers two supposedly transitive preference relations, designated by Indifference (I) and by Strict Preference (P), this method is based on the Fundamental System of Preference Relations (SFRP), also incorporating the weak preference relationship (Q). According to [12], there are several reasons why researchers seek to avoid the type of modeling that is based on the axiom of complete comparability and transitivity between alternatives, among which, can be mentioned the fact that the decision maker does not have all the information that allows him to choose one of the alternatives and by forcing a relationship of strict preference, or indifference, could lead to arbitrary and inconsistent errors. After the DMs establish the criteria and alternatives, the method can be divided into six steps: 
Step 1 - Ordinal transformation of the preferences of each DM, in each criterion, which are added at the end of this step, giving rise to a vector $\left(\mathrm{V}_{\mathrm{i}}\right)$, representing the weights of the criteria [10].

Let $c_{i}$ and $c_{j}$ be two criteria within a set of criteria $C=\left\{c_{1}, c_{2}, c_{3} \ldots c_{i}, c_{j}\right\}$. The degree of preference between them is given by: $\delta\left(c_{i} c_{j}\right)$. Table 2 shows the relationship of relative importance between the criteria:

Table 2. Relative importance between the criteria

\begin{tabular}{|c|c|c|}
\hline Scale 1 & Verbal representation & Scale 2 \\
\hline$\delta\left(\mathrm{c}_{\mathrm{i}} \mathrm{c}_{\mathrm{j}}\right) \ll 1 \leftrightarrow \mathrm{c}_{\mathrm{i}}<<<\mathrm{c}_{\mathrm{j}}$ & Absolutely less important & -3 \\
\hline$\delta\left(\mathrm{c}_{\mathrm{i}} \mathrm{c}_{\mathrm{i}}\right)$ そ $1 \leftrightarrow \mathrm{c}_{\mathrm{i}} \ll<\mathrm{c}_{\mathrm{i}}$ & Much less important & -2 \\
\hline$\delta\left(\mathrm{c}_{\mathrm{i}} \mathrm{c}_{\mathrm{i}}\right) \prec 1 \leftrightarrow \mathrm{c}_{\mathrm{i}} \quad<\mathrm{c}_{\mathrm{i}}$ & Less important & -1 \\
\hline$\delta\left(\mathrm{c}_{\mathrm{i}} \mathrm{c}_{\mathrm{i}}\right)=1 \leftrightarrow \mathrm{c}_{\mathrm{i}} \quad \approx \mathrm{c}_{\mathrm{i}}$ & Equally important & 0 \\
\hline$\delta\left(\mathrm{c}_{\mathrm{i}} \mathrm{c}_{\mathrm{j}}\right) \succ 1 \leftrightarrow \mathrm{c}_{\mathrm{i}} \quad>\mathrm{c}_{\mathrm{j}}$ & More important & 1 \\
\hline$\delta\left(c_{i} c_{j}\right) \succcurlyeq 1 \leftrightarrow c_{i}>c_{j}$ & Much more important & 2 \\
\hline$\underline{\delta\left(c_{i} c_{j}\right)} \gg 1 \leftrightarrow c_{i} \gg c_{j}$ & Absolutely more important & 3 \\
\hline
\end{tabular}

Let $\mathrm{D}$ be a set of decision-making agents, $\mathrm{D}=\left\{\mathrm{DM}_{1}, \mathrm{DM}_{2}, \ldots, \mathrm{DM}_{\mathrm{k}}, \ldots \mathrm{DM}_{\mathrm{n}}\right\}$ that express their opinions on the relative importance of the criteria involved. These preferences give rise to the $\mathrm{MDM}_{\mathrm{k}}$ preference matrix. The relationship between the two scales of the table allows the transformation of the matrix (1) into (2):

$\mathrm{MDM}_{\mathrm{k}}=\left[\delta\left(\mathrm{c}_{\mathrm{i}} \mathrm{c}_{\mathrm{j}}\right)\right]$, in a column vector $\left[\mathrm{V}_{\mathrm{i}}\right]$, where: $(1)$

$$
\mathrm{V}_{\mathrm{i}}=\sum_{j=1}^{m} \delta(\text { ci cj }) \quad(\mathrm{i}=1, \ldots, \mathrm{m}, \text { and } \mathrm{k}=1, \ldots, \mathrm{n})
$$

After generating the vector $\mathrm{Vi}$, its aij elements are normalized according to (3):

$\mathrm{v}=\left(\mathrm{a}_{\mathrm{ij}}-\min \mathrm{a}_{\mathrm{ij}}\right) /\left(\max \mathrm{a}_{\mathrm{ij}}-\min \mathrm{a}_{\mathrm{ij}}\right)$

Giving rise to the $\mathrm{DM}_{\mathrm{k}}$ preferences vector. If null values occur in this step, they are replaced by $1 \%$ of the second lowest value obtained. After all DM's carry out their evaluations, the normalized vectors are added, giving rise to the weight vector that expresses the importance of the criteria [10].

Step 2 - Ordinal classification $\left(\Theta_{\mathrm{ij}}\right)$ of the performance of the alternatives:

In this step, each DM assigns the ratings related to the performance of the alternatives in each criterion (table 3), which are related to their rating ranges $g_{(i j)}$. After all "n" DMs perform their evaluations, the arithmetic mean $\mu_{(\mathrm{ij})}$ of the classification ranges of the performances of the alternatives in each criterion is obtained.

Table 3. Ordinal ratings of performance of alternatives

\begin{tabular}{cc}
\hline $\begin{array}{c}\text { Ordinal classification }\left(\Theta_{\mathrm{ij}}\right) \text { of the performance of } \\
\text { alternative } \mathrm{i} \text { in criterion } \mathrm{j}\end{array}$ & Classification range $\mathrm{g}_{(\mathrm{ij})}$ \\
\hline Excellent $(\mathrm{E})$ & 1 \\
Very Good (VG) & 2 \\
Good (G) & 3 \\
Medium (M) & 4 \\
Bad (B) & 5 \\
Very Bad (VB) & 6 \\
Poor (P) & 7 \\
\hline
\end{tabular}


Step 3 - Obtaining the fractions of the criteria weights $\left(\sigma_{j(a b)}\right)$.

For each criterion " $\mathrm{j}$ ", a parity comparison is made between the alternatives to verify the relative distance between the mean values of the classification ranges (4):

$\Delta \mu_{\mathrm{i}(\mathrm{ab})}=\mu_{(\mathrm{ia})}-\mu_{(\mathrm{ib})}$

This value allows identifying in the preference modeling (figure 1 and table 4) the weight fraction of criterion " $\mathrm{j}$ ", obtained by alternative "a" in relation to alternative " $\mathrm{b}$ " $\left(\sigma_{j}(\mathrm{ab})\right)$.

Figure 1. Preference function of a criterion with linear variation [11].

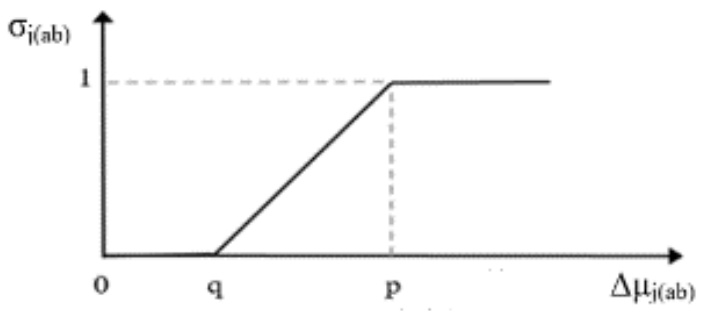

Table 4. Criteria preference modeling

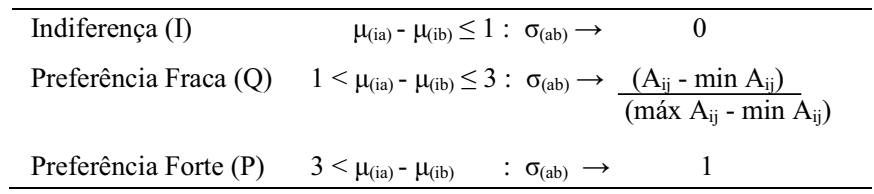

Step 4 - Calculation of relative $\mathrm{d}_{\mathrm{ab}}$ dominance.

Obtained by the weighted sum of the criteria weights $\left(\mathrm{w}_{\mathrm{j}}\right)$, with the corresponding fraction $\left(\sigma_{\mathrm{j}(\mathrm{ab})}\right)$ verified in the preference modeling $(5)$ :

$$
\mathrm{d}_{\mathrm{ab}}=\sum \mathrm{w}_{\mathrm{j}} \mathrm{x} \sigma_{\mathrm{j}(\mathrm{ab})}
$$

Step 5 - Calculation of Absolute $\mathrm{D}_{\mathrm{ab}}$ Dominance and Outranking Rate $\eta_{\mathrm{ab}}$ :

The difference between the relative dominances $d_{a b}-d_{b a}$ provides information on the absolute dominance Dab between the alternatives (6).

$\mathrm{D}_{\mathrm{ab}}=\mathrm{d}_{\mathrm{ab}}-\mathrm{d}_{\mathrm{ba}}$

By dividing $\mathrm{D}_{\mathrm{ab}}$, by the sum of the weights, the percentage rate of absolute dominance between the alternatives is obtained.

Step 6 - Assembling the graph with the dominance relationships between the alternatives (Optional).

\subsection{Application of SAPEVO-M-NC}

Tables 5 and 6 respectively present the values of the weights of the criteria, and the average performance of the alternatives after evaluation by $\mathrm{DM}_{1}$ and $\mathrm{DM}_{2}$ : 
Table 5. Weights of the criteria

\begin{tabular}{lccc}
\hline \multicolumn{1}{c}{ Criteria } & $\mathrm{DM}_{1}$ & $\mathrm{DM}_{2}$ & Final weight \\
\hline $\mathrm{C}_{1}$ - Profitability & 1 & 1 & 2 \\
$\mathrm{C}_{2}$ - Risk & 0,667 & 0,714 & 1,381 \\
$\mathrm{C}_{3}$ - Liquidity & 0,333 & 0,286 & 0,619 \\
$\mathrm{C}_{4}$ - Volatility & 0,3 & 0,143 & 0,146 \\
$\mathrm{C}_{5}$ - Initial application & 0,222 & 0,001 & 0,223 \\
\hline
\end{tabular}

Table 6. Average performance of alternatives in the criteria

\begin{tabular}{lccccc}
\hline Investment & Profitability & Risk & Liquidity & Volatility & initial application \\
\hline $\mathrm{A}_{1}$ (FJPF) & 6 & 1 & 1 & 1 & 1 \\
$\mathrm{~A}_{2}$ (FJPR) & 6,5 & 2 & 1,5 & 1,5 & 2 \\
$\mathrm{~A}_{3}$ (FM) & 1 & 4,5 & 5,5 & 2 & 5,5 \\
$\mathrm{~A}_{4}$ (FA) & 1 & 5,5 & 7 & 6,5 & 4 \\
$\mathrm{~A}_{5}$ (FC) & 2,5 & 5,5 & 1,5 & 4,5 & 1 \\
\hline
\end{tabular}

Table 7 presents the performance of the alternatives, the dominance relationships, and the percentage of the composition of the investment portfolios.

Table 7. The dominance relationships and the percentage of the composition of the investment portfolios

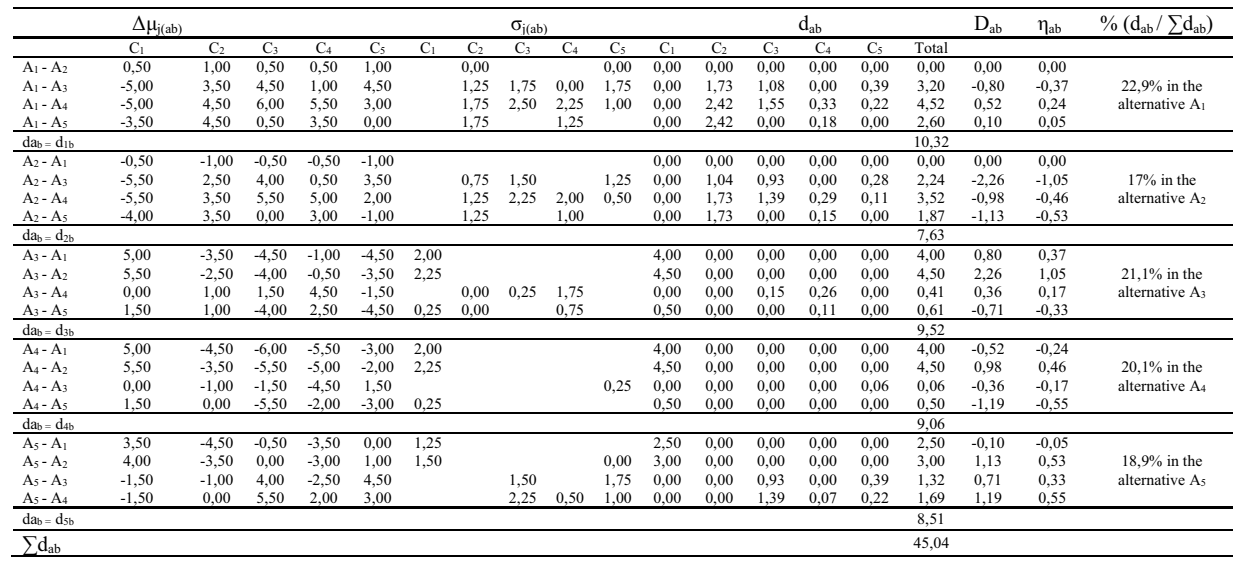

\section{Analysis of results and Conclusion}

The approach by the SAPEVO-M-NC method enabled a robust and efficient approach to solve the problem of structuring the investment portfolio in question, which considered, the evaluation of two analysts, the current scenario of the Brazilian economy and historical series of alternatives in the criteria in question, providing greater robustness and clarity to the investor in question. The financial contribution among the investments was distributed evenly, not showing on the part of the analysts a strong fear 
that would incite them to direct investments towards low risk, abdicating greater profits, nor an excess of confidence in an accelerated economic recovery, to explore alternatives with greater risks and initial contributions to obtain greater profits.

Due to the relative ease of application, associated with a low cognitive effort on the part of the evaluators, it appears that this methodology can provide great gains, not only for the academic community, but also for society as a whole, presenting itself as a alternative tool to support multicriteria decision, of an ordinal, non-compensatory nature and with the possibility of supporting multiple decision makers.

To carry out a more in-depth evaluation, as a proposal for future work, it is proposed to use other methods of multicriteria decision aid in the case studied, making a comparison with the method used.

\section{References}

[1] de Melo CML, Silva GAS, Melo ARS, de Freitas AC. COVID-19 pandemic outbreak: The Brazilian reality from the first case to the collapse of health services. An Acad Bras Cienc. 2020;92(4):1-14.

[2] Costa IP de A, Maêda SM do N, Teixeira LFH de S de B, Gomes CFS, dos Santos M. Choosing a hospital assistance ship to fight the Covid-19 pandemic. Rev Saude Publica. 2020;54, DOI: 10.11606/S15188787.2020054002792.

[3] Yi C, Zhan Y, Zhang J, Zhao X. Ownership structure and OFDI by EMNES: the moderating effects of international experience and migrant networks. Int J Emerg Mark. 2021;(March).

[4] Oliveira AS, Gomes CFS, Clarkson CT, Sanseverino AM, Barcelos MRS, Costa IPA, et al. Multiple Criteria Decision Making and Prospective Scenarios Model for Selection of Companies to Be Incubated. Algorithms. março de 2021;14(111), DOI: 10.3390/a14040111

[5] Tenório FM, dos Santos M, Gomes CFS, Araujo J de C. Navy Warship Selection and Multicriteria Analysis: The THOR Method Supporting Decision Making. In: Springer Proceedings in Mathematics and Statistics. 2020. p. 27-39, DOI: 10.1007/978-3-030-56920-4_3

[6] Jardim RRAJ, Santos M, Neto ECDO, Da Silva ED, De Barros FCMM. Integration of the waterfall model with ISO/IEC/IEEE 29148:2018 for the development of military defense system. IEEE Lat Am Trans. 2020;18(12):2096-103, DOI: 10.1109/TLA.2020.9400437

[7] De Barros MD, Salles CAL, Gomes CFS, Da Silva RA, Costa HG. Mapping of the scientific production on the ITIL application published in the national and international literature. Elsevier - Procedia Computer Science Procedia Computer Science 2015. p. 102-11, DOI: 10.1016/j.procs.2015.07.013

[8] Oliveira AO, Oliveira HLS, Gomes CFS, Ribeiro PCC. Quantitative analysis of RFID publications from 2006 to 2016. Int J Inf Manage. 2019;48:185-92, DOI: 10.1016/j.ijinfomgt.2019.02.001

[9] Pereira F de C, Verocai HD, Cordeiro VR, Gomes CFS, Costa HG. Bibliometric Analysis of Information Systems Related to Innovation. Procedia Comput Sci. 2015;55:298-307. DOI: 10.1016/j.procs.2015.07.052

[10] Gomes CFS, Santos M Dos, Teixeira LFH de S de B, Sanseverino AM, Barcelos MRDS. Sapevo-m: A group multicriteria ordinal ranking method. Pesqui Operacional. 2020;40:1-23.

[11] Maêda SM do N, Costa IP de A, Santos M dos., Gomes CFS. Economic and edaphoclimatic evaluation of Brazilian regions for African mahogany planting - an approach using the SAPEVO-M-NC ordinal method. In: Elsevier - Procedia Computer Science Procedia Computer Science. 2021.

[12] Gomes CFS, Gomes LFAM. Princípios e métodos para a tomada de decisão: Enfoque multicritério. 6th ed. Atlas Humanas Didático; 2019. 360 p. 